\title{
Puerperal Morbidity Following Caesarean Section in a Teaching Hospital in Ghana
}

\author{
David Mireku Aduama ${ }^{1, \text { *, }}$, Samuel A. Obed ${ }^{2}$, Joseph D. Seffah², Solomon K. Gumanga ${ }^{3}$ \\ ${ }^{1}$ Dept of Obstetrics \&Gynaecology, Achimota Hospital, Accra, Ghana \\ ${ }^{2}$ Dept of Obstetrics \& Gynaecology, Korle-Bu Teaching Hospital, University of Ghana Medical School, Accra, Ghana \\ ${ }^{3}$ Dept of Obstetrics \&Gynaecology, Tamale Teaching Hospital, University for Development Studies, Tamale, Ghana
}

Email address:

mirekuadu@hotmail.com (D. M. Aduama)

\section{To cite this article:}

David Mireku Aduama, Samuel A. Obed, Joseph D. Seffah, Solomon K. Gumanga. Puerperal Morbidity Following Caesarean Section in a Teaching Hospital in Ghana. Journal of Gynecology and Obstetrics. Vol. 3, No. 4, 2015, pp. 92-97. doi: 10.11648/j.jgo.20150304.15

\begin{abstract}
A prospective descriptive study was undertaken to determine the incidence and causes of puerperal morbidity after caesarean section in the department of Obstetrics and Gynaecology, Korle Bu Teaching Hospital from $1^{\text {st }}$ to $30^{\text {th }}$ June 2010. There were a total of 906 deliveries during the study period, of which 299 had caesarean section giving a caesarean section rate of $33 \%$. Primary caesarean section was $57.7 \%$. The incidence of puerperal morbidity after caesarean section was $45.6 \%$. Painful incisional site (21\%), puerperal febrile morbidity (16\%), depression $(12.0 \%)$ severe anaemia (12\%) Urinary tract infection $(6.2 \%)$ and wound infections $(5.8 \%)$ were the leading causes of puerperal morbidities. Other morbidities included hypertensive disorders $(4.2 \%)$, malaria $(3.2 \%)$ mastitis $(2.5 \%)$, postpartum haemorrhage $(2.1 \%)$, and endometritis $(1.2 \%)$. Conculsion: There was considerable maternal morbidity after caesarean section at the Korle Bu Teaching Hospital. There is a need for improvements in post operative care to reduce puerperal morbidity following caesarean section; adequate post operative pain management would reduce morbidity to a greater extent.
\end{abstract}

Keywords: Puerperal, Maternal, Post-Caesarean Section, Postpartum Morbidity

\section{Introduction}

The WHO defines the postpartum period, or puerperium, as beginning one hour after the delivery of the placenta and continuing until 6 weeks (42 days) after the birth of the infant [1]. Maternal morbidity refers to complications that have arisen during the pregnancy, delivery or in the postpartum period. Every year an estimated 50 million women are affected by maternal morbidity. Many of the complications leading to postpartum maternal morbidity arise during labour and delivery and in the first 1-2 weeks following delivery; for at least 18 million women these morbidities become longterm and are often debilitating[1]. Major acute obstetric morbidities include haemorrhage, sepsis and pregnancyrelated hypertension. Longer-term morbidities include uterine prolapse, vesicovaginal fistulae (VVF), dyspareunia and infertility[2].

Over the past decades, the nature and extent of postpartum maternal morbidity has received increasing interest in both developed and developing countries, with a range of research methods of varying sophistication being used to identify long and short-term and acute and chronic morbidity following childbirth[1-5].

It is recognized by professionals that women suffer greater morbidity after caesarean section compared with vaginal delivery. Caesarean section is a key operative procedure in maternal health care. During the past few decades the incidence of caesarean section has been increasing worldwide [6]. Reported caesarean delivery rates in SubSaharan Africa have ranged from $5 \%$ to $21.8 \%$ [7].The incidence of post caesarean puerperal morbidity has been reported to vary from $15 \%$ to as high as $86 \%[7-9]$.

In many developing countries health services data on postpartum morbidity remains extremely limited. In many settings, data from hospital-based studies is hard to interpret because of the small proportion of women that have access to supervised deliveries and medical care.The aim of the study was to determine the incidence of puerperal morbidity after caesarean section, the types of puerperal morbidity after caesarean section and the association between selected sociodemographic and medical factors and puerperal morbidity after caesarean section. 


\section{Methods and Subjects}

The study was conducted as a prospective descriptive study among post caesarean section patients in the department of Obstetrics and Gynaecology, Korle-Bu Teaching Hospital from $1^{\text {st }}$ June $2010-30^{\text {th }}$ June 2010.It is situated in Accra the capital city of Ghana. Annual deliveries at the Korle- $\mathrm{Bu}$ Teaching Hospital range between ten thousand $(10,000)$ and twelve thousand $(12,000)$, with a ceasarean section rate of $33-42 \%$. A sample size of 245 was determined based on Cochran Formula at 95\% confidence level, worst acceptable margin of error $5 \%$, at an estimated incidence rate of $15 \%$, the sample size was estimated to be 196 but to allow for non-response rate of ten percent $(10 \%)$ and non-participation rate of ten percent $(10 \%)$, two hundred and forty five (245) participants were used. The study protocol was given Ethical approval by the ethical and protocol review committee of the University of Ghana Medical School. The data was collected from antenatal card, labour ward records and operation records of all eligible pregnant women during the study period. The inpatient records were reviewed looking out for information on the occurrence and treatment of morbidities. Depression was diagnosed using ICD 10 depression diagnostic criteria. Patients with established infection, pyrexia of unknown origin before the caesarean section and those who underwent caesarean hysterectomy were excluded.

Frequencies and corresponding ninety five percent (95\%) confidence interval for discrete variables were used. Summary of continuous data and variables were presented in means and standard deviations. Chi squared test and the Odds Ratio (OR) with a 95\% confidence interval (CI) was use to describe the strength of association with a $p$ value of $<0.05$ considered to be statistically significant.

\section{Results}

There were two hundred and ninety nine (299) caesarean sections among nine hundred and six (906) deliveries during the period of the study, giving a caesarean section rate of thirty three percent $(33 \%)$.Four out of the two hundred and forty five (245) patients recruited into the study were lost to follow up therefore data from 241 subjects were used for analysis. Some results are summarized in table 1and 2 below.

Table 1. Showing age distribution, parity and frequency of antenatal visits of the patients.

\begin{tabular}{|c|c|c|c|c|}
\hline CHARACTERISTICS & & NUMBER & PERCENT & \\
\hline \multirow[t]{3}{*}{ Age (years) } & $<20$ & 6 & $2.5 \%$ & Mean 29.9 SD 5.2 \\
\hline & $20-34$ & 183 & $75.9 \%$ & \\
\hline & $\geq 35$ & 52 & $21.6 \%$ & \\
\hline \multirow[t]{3}{*}{ Parity } & Para 0-1 & 87 & $36.1 \%$ & Mean 2.2 SD 1.0 \\
\hline & Para $2-4$ & 141 & $58.3 \%$ & \\
\hline & Mulliparity $\geq 5$ & 13 & $5.4 \%$ & \\
\hline \multirow[t]{2}{*}{ Antenatal visit } & $\leq 3$ & 31 & $12.9 \%$ & Mean 6.8 SD 3.0 \\
\hline & 8 or more & 93 & $38.5 \%$ & \\
\hline
\end{tabular}

Table 2. Shows the gestational age at delivery, duration of labour and the state of the membranes.

\begin{tabular}{|c|c|c|c|c|}
\hline CHARACTERISTICS & & NUMBER & PERCENT & \\
\hline \multirow[t]{4}{*}{ Gestational Age at delivery } & $28-32$ & 9 & $3.7 \%$ & Mean 38.1 SD 2.4 \\
\hline & $33-36$ & 22 & $9.2 \%$ & \\
\hline & $37-40$ & 180 & $74.7 \%$ & \\
\hline & $\geq 41$ & 30 & $12.4 \%$ & \\
\hline \multirow[t]{3}{*}{ Duration of labour } & Not applicable & 124 & $51.4 \%$ & \\
\hline & $\leq 14$ hours & 103 & $42.7 \%$ & \\
\hline & $>14$ hours & 14 & $5.8 \%$ & \\
\hline \multirow{2}{*}{ State of the membranes } & Membranes ruptured $(<24$ hours $)$ & 75 & $29.4 \%$ & \\
\hline & Intact membranes & 159 & $66.0 \%$ & \\
\hline
\end{tabular}

Not applicable: These groups were made up of the elective caesarean sections and other emergencies like severe pre-eclampsia, abruptio placentae with unfavorable cervix etc.

One hundred and seventeen (48.5\%) women had been through labour before the caesarean section and of these 14 $(12 \%)$ had been in labour for longer than 14 hours. The gestational age at delivery varied from 28 weeks to 41 weeks and over.

One hundred and thirty-nine women (57.7\%) had a primary caesarean section; 64 women $(26.6 \%)$ had had one previous caesarean section, $32(13.3 \%)$ two previous caesarean sections and $6(2.5 \%)$ three previous caesarean sections. Thirty $(33.7 \%)$ of the elective caesarean sections were primary caesarean section while $31(34.8 \%)$ had history of previous caesarean section. One hundred and nine (77\%) of the emergency caesarean section were primary caesarean sections.

The commonest medical conditions were sickle cell disease $(32,13.3 \%)$ and anaemia from other causes (34, $14.2 \%)$. Thirty-five subjects $(14.2 \%)$ had other diseases such as asthma, hepatitis, malaria, urinary tract infection and cardiac diseases. Eighteen (7.6\%) had more than one medical 
condition. None of the subjects had diabetes mellitus. A summary of the medical conditions of the patients is

presented in figure 1 below.

\section{Chronic}

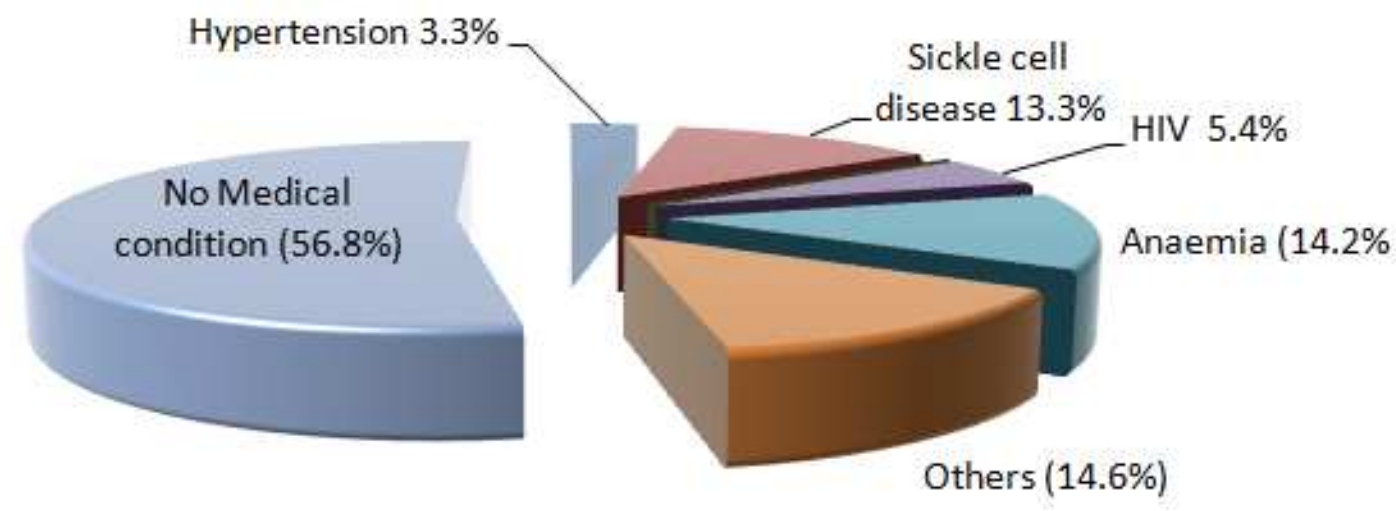

Figure 1. Medical conditions of patients in the study.

Eighty-nine $(36.9 \%)$ of the Caesarean sections were elective and $152(63.1 \%)$ emergency procedures. Most of the Caesarean sections, 131 (54.4\%), were performed by junior residents, $71(29.5 \%)$ by senior residents and $26(10.8 \%)$ by consultants. Thirteen $(5.4 \%)$ were performed by house officers under supervision.

Two hundred and seventeen $(90 \%)$ of the surgeries lasted between 30 and 60 minutes, 11 (4.6\%) less than 30 minutes and $2(0.8 \%)$ more than 90 minutes. Twenty-eight patients received blood transfusions of 1-4 units with a mean of 2.3(SD1.0) for indications including placenta praevia, placental abruption and postpartum haemorrhage. Intraoperatively $230(95.4 \%)$ of the patients received antibiotics with $9(3.7 \%)$ commencing antibiotics postoperatively and $2(0.8 \%)$ preoperatively. Two hundred and thirty $(95.4 \%)$ of the caesarean section resulted in livebirth while $11(4.6 \%)$ had stillbirth. There was no maternal death among women who had caesarean section during the study period. Figure 2 below shows the various indications for caesarean section in the study. Some patients had one or more indications for the caesarean sections but the leading indication for each caesarean section was used.

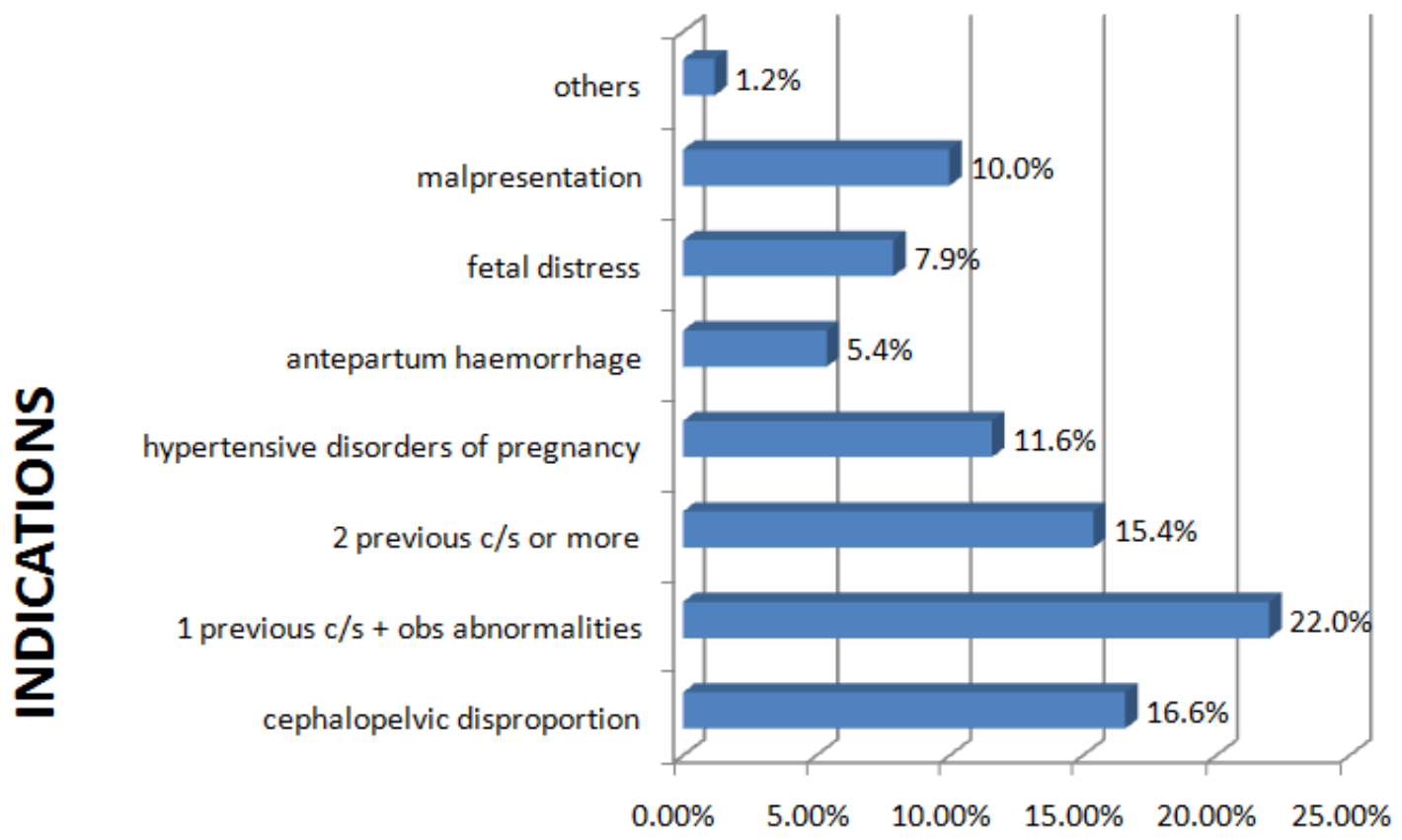

\section{PERCENTAGES}

Figure 2. Indications for caesarean section at the KBTH, June 2010.

One hundred and ten of the patients had one elemento fmorbidity or the other giving the incidence of puerperal morbidity after caesarean section to be $45.6 \%$ with 36 $(14.8 \%)$ of the patients having two or more elements. Table 3 
below shows details of puerperal morbidity after caesarean section.

Table 3. Puerperal morbidity after caesarean section in KBTH, June 2010.

\begin{tabular}{lllll}
\hline Types of Morbidity & $\mathbf{1}^{\text {st }}$ week postpartum & Postpartum visit & Total Morbidity & Percent (\%) N=241 \\
\hline Painful incisional site & - & 51 & 51 & $21.2 \%$ \\
Depression & 9 & 20 & 29 & $12.0 \%$ \\
Severe anaemia & 21 & 8 & 29 & $12.0 \%$ \\
Constipation & - & 19 & 19 & $9.1 \%$ \\
Tiredness & - & 17 & 17 & $7.2 \%$ \\
Urinary tract infection & 10 & 5 & 15 & $6.2 \%$ \\
Wound infections & 8 & 6 & 14 & $5.8 \%$ \\
High blood pressure & - & 10 & 10 & $4.2 \%$ \\
Malaria & 6 & 2 & 6 & $3.2 \%$ \\
Mastitis & 6 & - & 3 & $2.5 \%$ \\
Postpartum haemorrhage & 3 & - & 3 & $1.2 \%$ \\
Endometritis & 3 & - & 1 & $1.2 \%$ \\
Postpartum Eclampsia & 1 & - & 1 & $0.4 \%$ \\
Respiratory tract infection & 1 & - & 5 & $0.4 \%$ \\
Re-admission & - & 5 & & $2.1 \%$ \\
\hline
\end{tabular}

Mastitis, wound infections, urinary tract infections and severe anaemia occurred mostly within the first week postpartum, while depression, constipation, painful incisional site and tiredness occurred at the postpartum visit. Five patients were readmitted on account of puerperal sepsis, postpartum eclampsia, severe respiratory tract infection, secondary postpartum haemorrhage and congestive cardiac failure secondary to severe anaemia. High blood pressure, painful incisional site, constipation and depression were present only at the sixth week visit. Comparison of puerperal morbidity and selected risk factors are shown in table 4 below.

Table 4. comparison of puerperal morbidity and selected risk factors.

\begin{tabular}{llll}
\hline \multirow{2}{*}{ RISK FACTORS } & & $\begin{array}{l}\text { Morbidity at } \mathbf{1}^{\text {st }} \text { week Frequency \% OR 95\%CI P } \\
\text { value }\end{array}$ & $\begin{array}{l}\text { Morbidity at 6 } \\
\text { value }\end{array}$ \\
\hline $\begin{array}{l}\text { Types of } \\
\text { caesarean }\end{array}$ & Elective & $31.51 .10 .6-2.00 .73$ & $55.11 .0 .6-1.80 .92$ \\
section & Emergency & 35.5 & 52.3 \\
$\begin{array}{l}\text { Number of } \\
\text { caesarean }\end{array}$ & Primary & $40.20 .70 .4-1.20 .22$ & $23.11 .10 .6-1.90 .81$ \\
section & Repeat & 55.1 & 30.8 \\
Duration of & $<60$ min & $34.70 .60 .2-2.30 .51$ & $23.1 .320 .1-1.10 .07$ \\
surgery & $>60$ min & 56.6 & 30.8 \\
Antenatal & Nonattendant & $29.01 .30 .6-3.10 .52$ & $34.82 .31 .0-5.00 .04$ \\
attendance & Attendant & 38.7 & 57.6 \\
Rank of operator & Con/SnrRs & $30.91 .20 .7-2.10 .54$ & $36.11 .10 .6-1.80 .82$ \\
& Jnr Rs/HO & 54.6 & 55.6 \\
\hline
\end{tabular}

OR: odds ratio CI: $95 \%$ confidence interval

Associations between the comparisons made above were not statistically significant. Table 5 below provides more information on some risk factors and development of puerperal morbidity after caesarean section.

Table 5. Association between risk factors and puerperal morbidity after caesarean section (first week postpartum) (six weeks postpartum)

\begin{tabular}{|c|c|c|c|c|c|}
\hline Variable & Sample (N) & Chi-Squared Test $\left(\chi^{2}\right)$ & p-value sig (2-tailed) & Chi-Squared Test $\left(\chi^{2}\right)$ & p-value sig (2-tailed) \\
\hline Medical conditions & 241 & 11.092 & 0.002 & 32.089 & 1.000 \\
\hline Ruptured Membranes & 241 & 27.912 & 0.830 & 32.867 & 0.474 \\
\hline Antenatal Complications & 241 & 15.292 & 0.793 & 13.252 & 0.894 \\
\hline Rank of Operator & 241 & 45.851 & 0.126 & 71.613 & 0.000 \\
\hline Indication of $\mathrm{C} / \mathrm{S}$ & 241 & 84.632 & 0.460 & 83.510 & 0.286 \\
\hline Timing of antibiotics & 241 & 5.527 & 1.000 & 15.150 & 0.865 \\
\hline
\end{tabular}

Chi square test $\left(\chi^{2}\right)$ was used to test for the association. The presence of a medical condition in the patients was statistically significant during the first week with a $(\mathrm{p}=0.002)$. There was no difference in morbidities among patients operated on by the different ranks of surgeons at first week ( $\mathrm{p}=0.126)$, but rank operator was statistically significant at six weeks $(\mathrm{p}<0.0001)$. 


\section{Discussion}

An incidence of puerperal morbidity after caesarean section of $45.6 \%$ was found in this study, which is similar to $44.4 \%$ in Maiduguri [3] but higher than $39.3 \%$ in Benin [10] and $35.7 \%$ in the Netherland [11]. The incidence largely depended on the definition of puerperal morbidity used in the various studies. In this study a broad definition of maternal morbidity was used [1,2] and this may explain the high incidence. It is known that studies that measured the validity of women's self-reports of delivery-related complications and morbidity by comparing them with medically diagnosed conditions found that self-reported morbidity overestimates the incidence of medically diagnosed morbidity[12].This could partly account for the high incidence of self-reported ill health in this study. However perceived morbidity is important for policy planners. Attention is drawn to what worries women about their health, based on a criteria of seriousness such as discomfort, interference with their daily routine or with their feelings of dignity [13].

The top five leading causes of puerperal morbidity after caesarean section in this study were Painful incisional site (21\%), depression (12.0\%) severe anaemia (12\%) urinary tract infection $(6.2 \%)$ wound infections $(5.8 \%)$. The low rate of severe morbidity (haemorrhage, postpartum eclampsia and puerperal sepsis) may account for a low rate of readmission $(2.1 \%)$ that was found in this study.

Most of the complaints of painful incisional site were reported at the sixth week of postpartum visit, when it was expected that the wound would have healed. In the first week after the caesarean section patients usually received routine analgesia and some mental resolution that surgery is associated with pain, but pain that persist longer can be of more concerned at six weeks if it is still present. The incidence of depression among the study group was $12 \%$. A study by Hillian E.M. found a much higher incidence of $38 \%[14]$. Some suggested explanation for the depression includes, women complaining about lack of support from their partners especially in a society where women are largely dependent on their husbands financially, long hospital stay and lastly, women not satisfied with the mode of delivery. Indeed it has been shown that most women who undergo caesarean birth experience a feeling of resentment towards the physician, profound disappointment at treatment expectation and lost of the happy moment of natural birth; these have been known to lead to depression [15].

Abdominal wound infection occurred among 5.8\% of the patients who had caesarean section in our study. It is much lower compared with $15.1 \%$ at Komfo Anokye Hospital Kumasi [16]. All the patients in the study had some form of antibiotic therapy with $95.4 \%$ receiving prophylactic antibiotics intra-opeatively. This may account for the lower incidence of wound infection after caesarean section.

In this study, presence of a medical condition $(P=0.002)$ and rank of operator $(\mathrm{P}<0.0001)$ showed significant association with puerperal morbidity after caesarean section. Some authors have implicated various factors for the development of puerperal morbidity after caesarean section, whiles Baskett et al[17] and Van Ham et al[11] found no risk factors, other authors found that factors such as duration of labour more than twelve hours, number of vaginal examination, absence of prophylaxis with antibiotics and anaemia, among others to be risk factors for the development of puerperal morbidity after caesarean sections[11].

Presence of a medical condition at the first week post caesarean section had significant risk for the development of puerperal morbidity than six weeks postpartum visit. This may be explained by the fact that the medical conditions identified in the study, that is sickle cell disease, anaemia, retroviral infections and hypertensive disorders usually get worse in pregnancy especially at the time of delivery, but by the six week period these patients medical conditions would have improved because of treatment they have received and are most likely to have fewer morbidities.

In this study, the urgency of caesarean section, number of caesarean sections and the duration of caesarean sections did not increase the risk for developing puerperal morbidity after caesarean section. This contradicts the study done by Hillian E.M[14]in which women delivered by emergency caesarean section experienced a greater number of postnatal problems. Work done by Brumffield CG et al[18]and Noyes N et al[19] showed that endometritis complicated $5-15 \%$ of scheduled caesarean section, rose to $30-35 \%$ if caesarean section was done after an extended period of labour but falls to $15-20 \%$ if the patient received prophylactic antibiotics

In conclusion, the study showed that there was considerable puerperal morbidity after caesarean section at the Korle $\mathrm{Bu}$ Teaching Hospital. There is a need for improvements in post operative care to reduce puerperal morbidity following caesarean section; adequate post operative pain management would reduce morbidity to a greater extent. Limitation of this study is that it had low power to evaluate less common conditions like deep vein thrombosis and puerperal psychosis etc.

\section{References}

[1] World Health Organization. Postpartum care of mother and newborn: a practical guide WHO/RHT/MSM/983. Geneva: WHO; 1998.

[2] Koblinsky MA, Tinker A, Daly P. Programming for safe motherhood: a guide to action. Health Policy Plan. 1994; 9:252-266.

[3] Chama CM, El-Nafaty AU, Idrisa A. Caesarean morbidity and mortality at Maiduguri, Nigeria. J ObstetGynaecol. 2000; 20:45-48.

[4] Waterstone M, Wolfe C, Hooper R, Bewley S. Postnatal morbidity after childbirth and severe obstetric morbidity. BJOG. 2003; 110:128-133. 
[5] Fikree FF, Ali T, Durocher JM, Rahbar MH. Health service utilization for perceived postpartum morbidity among poor women living in Karachi. SocSci Med. 2004; 59:681-694. Doi: 10.1016/j.socscimed.2003.11.034.

[6] Wilkinson C, Mclllwaine G, Boulton-Jones C, Cole S. Is a rising caesarean section rate inevitable? BJOG 1998; 105(1):45-52.

[7] Dumont A, De Bernis L, Bouvier-ColleMH, Breart G. Caesarean section rate for maternal indication in sub-Saharan Africa: a systematic review. Lancet 2001;358(9290):1328-33

[8] Villar J, Valladares E, Wojdyla D, Zavaleta N, Carroli G, Velazco A, et al. Caesarean delivery rates and pregnancy outcomes: the 2005 WHO global survey on maternal and perinatal health in Latin America. Lancet 2006; 367(9525): 1819-29

[9] Villar J, Carroli G, Zavaleta N, Donner A, Wojdyla D, Faundes A, et al. Maternal and neonatal individual risks and benefits associated with caesarean delivery: multicentre prospective study. $B M J 2007 ; 335(7628): 1025$

[10] Okonta Pl, Otoide VO, Okogbenin S. Caesarean section at the University of Benin Teaching Hospital revisited. Trop J ObstetGynaecol 2003; 20: 63-66

[11] Van Ham MA, Van Dongen PW, and Mulder J, Maternal consequences of CS. A retrospective study of intra-operative and posto-perativematernal complicationsof CS during a ten year period Eur J. Obstet, Gynecol. Reprod. Biol 74(1) 1-6 1997.
[12] Sloan NL, Amoaful EA, Winikoff P. Adjei S. Validity of women's self-reported obstetric complications in rural Ghana. J Health PopulNutr 2001; 19(2): 45-51

[13] Zurayk H, Khattab H, Younis N, ELMouelhy M, Fadle M. Concepts and measures of reproducted morbidity. Health Transit Rev. 1993; 3: 17-40

[14] Hillian EM. Postoperative morbidity following caesarean delivery. $J$ AdvNurs 1995; 22: 1035 - 42

[15] Cepicky P, Stembera Z, Zeman V, Lomickova T, Mandys F. When is it possible to meet the wish of a woman to terminate her labour by caesarean section? Europ J obstetGynaecol $1990 ; 38 ; 109-112$

[16] Danso KA. Abdominal wound infection complicating caesarean section. GhanaMed J 1998, 32 b: 1003-9

[17] Tran TS., Jamulitrat S; Chongsuvivatwong V. Greater A. Risk factors for post caesarean surgical site infection. Obstet and GynaecolVol 95, Number 3, March 2000, 367-371(5)

[18] Brumffield CG, Hauth JC, Andrews WW. Puerperal Infection after cesarean delivery: evaluation of a standardized protocol. Am J ObstetGynecol 2000 May; 182(5): 1147-51

[19] Noyes N, Berkelej AS, Freedman K. Incidence of postpartum endomyometritis following single dose antibiotic prophylaxis in high risk caesarean section patients. Infect Dis ObstetGynaecol 1998; 6(5):220-3. 